\title{
Article
}

\section{Testing a One-Item Risk Measure to Predict Alameda Seven Health Behaviors in the Republic of Korea}

\author{
Donata Bessey
}

check for

updates

Citation: Bessey, D. Testing a

One-Item Risk Measure to Predict Alameda Seven Health Behaviors in the Republic of Korea. Int. J. Environ. Res. Public Health 2021, 18, 300. https://doi.org/ijerph18010300

Received: 24 November 2020 Accepted: 30 December 2020 Published: 3 January 2021

Publisher's Note: MDPI stays neutral with regard to jurisdictional clai$\mathrm{ms}$ in published maps and institutional affiliations.

Copyright: (C) 2021 by the author. Licensee MDPI, Basel, Switzerland. This article is an open access article distributed under the terms and conditions of the Creative Commons Attribution (CC BY) license (https:// creativecommons.org/licenses/by/ $4.0 /)$.
East Asia International College, Yonsei University, Mirae Campus, Wonju 26493, Korea; dbessey@yonsei.ac.kr; Tel.: +82-33-760-2276

\begin{abstract}
The college years provide an important window of opportunity for the implementation of preventive efforts, especially with respect to smoking, problematic drinking, and obesity. Targeting of individuals at high risk of adopting those health behaviors might increase the effectiveness of those efforts, yet little is known about possible criteria for targeting and their ability to predict the adoption of risky health behaviors. Human capital theory predicts that more risk-averse individuals are more likely to invest in their health capital and should therefore be less likely to engage in risky health behaviors. Building on this theoretical prediction, this study uses a simple one-item measure of risk attitude and examines its ability to predict the Alameda Seven health behaviors in a sample of college students in the Republic of Korea. Unlike previous research, it also controls for personality traits and cognitive ability. Experimental data were gathered and analyzed using regression analysis. The risk measure predicted the probability of smoking and reporting higher stress levels, with no correlations found for the other health behaviors, suggesting that replication studies using larger samples should be carried out to analyze if these findings persist.
\end{abstract}

Keywords: health behaviors; personality traits; cognitive ability; risk attitude

\section{Introduction}

According to the World Health Organization's latest "Global Burden of Disease" report, high systolic blood pressure, fasting plasma glucose, and body mass index were the three risk factors associated with the most pronounced increases in exposure and related losses in disability-adjusted life years (DALYs) between 2010 and 2019 [1]. These risk factors are preventable; therefore, the development of preventive efforts for lifestyle-related diseases has become a public health policy objective in many high-income countries including the United States, Australia, and Denmark [2-4]. In the next decades, the number of patients with those diseases is projected to increase further [5-7], putting an additional strain on healthcare systems.

In their college years, most students live in dorms, or other forms of housing, away from their parental home, and many engage in new health behaviors that shape their lifestyles [8,9] such as smoking [10], binge drinking [11], or eating behaviors that lead to weight gain [9] and contribute to obesity levels, particularly in the United States [12]. While initiation to and experimentation with smoking usually take place in adolescence, transition to regular use typically occurs during the college years [10]. Smoking cessation before age 30 dramatically decreases the risk of smoking-related mortality [13], suggesting that the college years are a particularly important window of opportunity for preventive efforts to be implemented.

When deciding on target populations for preventive efforts, one approach could be to develop simple markers to identify those at risk of adopting unhealthy behaviors (or unlikely to adopt healthy ones) and provide them with tailored preventive measures and programs [14]. Previous evidence, as summarized in two review articles [15,16], suggests that targeted preventive health check-ups in general practice might be beneficial 
for high-risk individuals. Instead of health check-ups, this research is informed by economic decision-making theory to derive a possible predictor of the probability of engaging in health behaviors. Human capital theory, developed by Becker [17] and Grossman [18], and extended to risky investments [19-21], provides an economic analysis of individual decisions to invest in health and predicts that more risk-averse individuals are more likely to invest in their health capital and should therefore be less likely to engage in risky health behaviors. This study uses a simple one-item measure of risk attitude (as suggested by Dohmen et al. [22], henceforth " $\mathrm{D}$ ") and analyzes its ability to explain the probability of adopting the Alameda Seven health behaviors (smoking, drinking excessively, exercising, following a healthy diet, being overweight or obese, experiencing stress, and sleeping enough), using data collected in an experiment. These seven health behaviors were first analyzed in 1965 in an epidemiological study in Alameda County, California. Empirical research shows that some, or all, of the Alameda Seven affect physical health status [23-28]. While there is a strand of literature in health economics that employs risk measures elicited in incentivized economic experiments or other proxy measures of risk, these measures are typically "expensive" both in terms of money and time required in surveys to be administered. Dohmen et al. [22] therefore propose a one-item risk attitude measure that is correlated with other risk measures, such as choices in incentivized lotteries on one hand, and predicts a number of different risky behaviors, such as choosing a risky occupation or choosing to smoke, on the other. The fact that $\mathrm{D}$ has been found to predict more risky health behaviors than other measures [29] and that its ability to predict risky health behaviors has been confirmed [30], provided the rationale to analyze its usefulness as a predictor of a full set of health behaviors and outcomes in an experiment using college students as subjects. Unlike this previous research using D to predict only a small number of risky health behaviors, this study analyzes the full set of Alameda Seven health behaviors.

Additionally, this research is related to two strands of the literature in health psychology. The first one analyzes correlations between Big Five personality traits and health behaviors [31-37] and the second analyzes correlations between cognitive ability and health behaviors [38-42]. Those strands of literature showed important effects of both ability and personality, suggesting that failure to include information on those traits could lead to omitted variable bias in regressions of the determinants of health behaviors and provide the rationale to include a measure of cognitive ability as well as information on respondents' Big Five personality traits in regression analyses. Previous research in economics also shows a relationship between cognitive ability and risk-taking [43], adding further evidence for the need to include a measure of cognitive ability.

This study aims to test the suitability of a one-item risk measure (D) as a predictor of the probabilities of engaging in Alameda Seven health behaviors, using an experimental study approach and a sample of college students. Unlike the scant previous evidence $[29,30]$, it also includes information on subjects' Big Five personality traits derived from a 15 -item inventory $[44,45]$ and an ultra-short measure of cognitive ability $[46,47]$ in regression analyses.

\section{Materials and Methods}

\subsection{Theoretical Considerations}

Human capital theory was first developed by Becker [17] with an application to education and Grossman [18] with an application to health investment, and later extended to the analysis of risky investments [19-21]. It provides a framework for analysis of the decision to engage in health behaviors with uncertain outcomes as risky investments in human capital. Individual risk attitudes measured using a variety of elicitation methods are a key determinant of human capital investment decisions. Human capital theory predicts that more risk-averse individuals are more likely to invest in their health capital and should therefore be less likely to engage in risky health behaviors, and are more likely to engage in beneficial health behaviors. 


\subsection{Data Collection, Experimental Methods and Questionnaires}

Data were collected at a college campus in Gangwon-do, Republic of Korea. Freshmen students were recruited as subjects, with no restrictions on major, age, or gender.

After a pretest, three experimental sessions were conducted between March and April 2018, with a total of 178 subjects participating. After deleting observations with missing values, $n=131$ subjects remained. For basic demographics of the sample and a correlation matrix, please refer to Tables A2 and A3 in Appendix A. The following flowchart presents an overview of the experimental design (Figure 1).

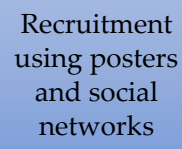

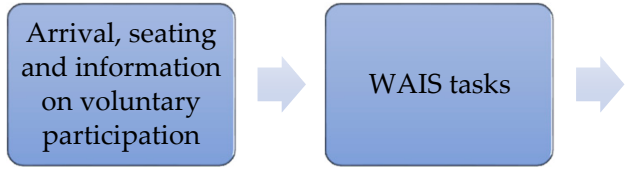

Figure 1. Experimental design.

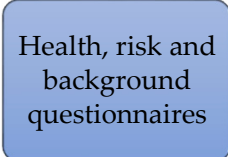

Health, risk and questionnaires
Payments and end of the experiment

In all experimental sessions, subjects first were welcomed to the experiment, and were informed about the study, the procedures, and their rights regarding voluntary participation. Next, they completed the Animal Naming Task and the Symbol Correspondence Task, which are from the Wechsler Adult Intelligence Scale (WAIS). These tasks were intended to serve as a measure of cognitive ability. Previous studies suggest that scores for these tasks are highly correlated with scores on other submodules of the WAIS and other widely used intelligence tests [46,47]; therefore, they can serve as a measure of cognitive ability without taking a long time to complete. In this research, only the scores for the Animal Naming Task could be used as a measure of cognitive ability because the majority of subjects approached the Symbol Correspondence Task in an incorrect way, i.e., instead of filling in symbols in a row, as the Symbol Correspondence Task requires, subjects first filled in one symbol for the entire task and then the next, causing the scores to be disregarded.

In the next stage of each experimental session, subjects answered a health questionnaire containing items related to the Alameda Seven health behaviors. The health behaviors included in this research were the original Alameda Seven: smoking, drinking excessively, being overweight or obese, experiencing stress, following a healthy diet, exercising, and sleeping enough. These behaviors were measured based on the subjects' answers to questions from the Canadian Community Health Survey 2016 [48], which can be found in Appendix B.

After the health survey, subjects answered a 15-item short version of the Big Five inventory that was developed and validated for use in the German Socio-Economic Panel $[44,45]$. The Big Five are five dimensions which define human personality at the broadest level, based on the following descriptors of language [49,50]: extraversion, agreeableness, conscientiousness, emotional stability, and openness to experience. Previous research suggests that the Big Five personality traits predict health-related behaviors and outcomes [31-37].

The Big Five personality inventory was scored identically to the original research $[44,45]$ and was not standardized. In this part of each experimental session, subjects also answered the following question: "How willing are you to take risks, in general?" [22]. Respondents rated their willingness on a scale from 1 to 10 , where higher values corresponded to higher willingness to take risks. Previous studies $[24,25]$ suggest that this risk measure predicts several risky health behaviors.

Lastly, the subjects answered a questionnaire containing items about their gender, age, and family background, and were paid for their participation in the experiment.

More detail about the experimental procedures, the tasks from the WAIS subscales, the 15-item Big Five inventory, and the health and background questionnaires are shown in Appendix B. 


\subsection{Statistical Methods}

The empirical analysis of the experimental data was carried out using STATA 16.1. First, the following seven regression models were estimated: for the determinants of smoking status, a simple probit model was estimated; for the determinants of number of alcohol binges during the week prior to the experiment, level of stress, sleep quality, BMI, general health, and general mental health, ordered probit models were estimated; for the determinants of nutritional quality and minutes of exercise, ordinary least squares models were estimated. All estimations included the following control variables: gender, age, an income measure (as the answer to the question "How difficult is it for you to raise 100,000 Won for personal consumption?", with $1=$ very easy and $5=$ very hard), the respondents' number of siblings, and a measure of family background (as the answer to the question "Did you have a happy childhood?" with $1=$ very unhappy and $5=$ very happy). Second, predicted probabilities of engaging in the Alameda Seven health behaviors were plotted for one-step increases in the D measure. As these plots tend to become confusing for ordered outcomes (such as most of the dependent variables analyzed here), all outcomes were binarized and plots for those probit regressions are presented, at the cost of loss of information about the dependent variables. The outcomes were binarized as follows: a value of 1 was assigned for having had any binge drinking episode during the week before the experiment, for experiencing "fairly high" or "very high" stress levels, for reporting above-average sleep quality, for having a BMI above 23 (following the Korean Society for the Study of Obesity's 2018 suggestion to create a category of "pre-obesity" for Korean individuals with a BMI above 23 and under 25 [51]), for exercising for an average of at least 30 min per day, and for having fruits or vegetables at least once daily. Predicted probabilities and the corresponding plots were calculated and graphed using the margins command in STATA 16.1, for increases in one of the D risk measures. All other variables were held constant at the sample means, with the exception of the ordered variables, which were held constant at the sample modes.

\section{Results}

Table 1 presents descriptive statistics. The average age of the subjects was 19.3 years and 76 were female. A binge drinking episode in the week before the experiment was reported by $71.76 \%$ of the participants and $11.45 \%$ reported that they were smokers. On average, the subjects reported exercising for $166 \mathrm{~min}$ in the week before the experiment and mean self-reported BMI in the sample was 22.1. A correlation matrix is provided in Appendix A, Table A1.

Table 1. Basic descriptive statistics.

\begin{tabular}{ccccc}
\hline & Mean & Std. Dev. & Min & Max \\
\hline Last week binge (0 = never, 3 = daily) & 1.1527 & 0.8899 & 0 & 3 \\
Smoker (1 = yes) & 0.1145 & 0.3196 & 0 & 1 \\
Stress (1 = not at all, 5 = extremely stressful) & 2.9008 & 0.7830 & 1 & 4 \\
Sleep quality (index, 5 = high) & 3.5038 & 0.5583 & 1.3333 & 5 \\
Nutrition quality (times fruit/vegetables eaten) & 6.4351 & 3.4061 & 0 & 14 \\
Exercise (minutes) & 172.5954 & 185.1084 & 0 & 960 \\
BMI (weight/height $\left.{ }^{2}\right)$ & 0.2214 & 0.4850 & 0 & 2 \\
Celf-rated risk tolerance D (1 = low, 10 = high) & 5.2977 & 2.3557 & 1 & 10 \\
Cognitive ability measure & 22.9618 & 4.9418 & 12 & 40 \\
Big 5 Openness & 4.7939 & 1.1741 & 1.6667 & 7 \\
Big 5 Conscientiousness & 4.1298 & 0.9586 & 2 & 7 \\
Big 5 Extraversion & 4.7150 & 1.2363 & 1 & 7 \\
Big 5 Agreeableness & 4.8372 & 0.9468 & 2.6667 & 6.6667 \\
Big 5 Neuroticism & 4.6005 & 1.0785 & 1 & 7 \\
Income measure (1 = very easy, 5 = very hard) & 3.3817 & 0.9237 & 1 & 5 \\
\hline
\end{tabular}


Table 1. Cont.

\begin{tabular}{ccccc}
\hline & Mean & Std. Dev. & Min & Max \\
\hline Female (1 = female) & 0.5802 & 0.4954 & 0 & 1 \\
Age (years) & 19.2901 & 0.8273 & 18 & 24 \\
Number of siblings & 1.1603 & 0.6179 & 0 & 4 \\
Happy childhood (1 = very unhappy, 5 = very & 3.9542 & 0.8025 & 2 & 5 \\
happy) & & & \\
\hline
\end{tabular}

Table 2 presents results from seven regressions for the determinants of the Alameda Seven health behaviors, using the D risk measure and a full set of control variables. The estimated coefficients of interests are reported here and full regression results including all control variables can be found in the Appendix A, Table A2. In addition, results from regressions without any control variables and with only a basic set of control variables are provided in the Appendix A, Tables A3 and A4.

Table 2. D with personality and ability measures (estimated coefficients from probit, ordered probit, and ordinary least squares regressions).

\begin{tabular}{cccccccc}
\hline & Smoker & Binges & Stress & Sleep & \multicolumn{2}{c}{ BMI } & \multicolumn{2}{c}{ Nutrition } & \multicolumn{2}{c}{ Physical Activity } \\
\hline & $($ probit $)$ & $($ oprobit $)$ & (oprobit) & (oprobit) & (oprobit) & (OLS) & $($ OLS) \\
\hline $\mathrm{D}$ & $0.1641^{*}$ & 0.0025 & $-0.1001^{* *}$ & 0.0051 & 0.0306 & 0.1012 & 0.6814 \\
& $(0.0854)$ & $(0.0481)$ & $(0.0502)$ & $(0.0456)$ & $(0.0696)$ & $(0.1431)$ & $(7.7992)$ \\
\hline
\end{tabular}

Notes: Standard errors are given in brackets. ${ }^{* *}$ denotes $5 \%$, and ${ }^{*}$ denotes $10 \%$ significance levels.

The results show that D performed poorly as a predictor of Alameda Seven health behaviors and health outcomes. D was positively correlated with the probability of being a smoker, and negatively correlated with perceived stress levels.

For the control variables, cognitive ability was found to be positively correlated with nutrition quality in regressions. From the Big Five, conscientiousness was negatively correlated with BMI, extraversion was positively correlated with the probability of being a smoker, binge drinking, sleep quality, nutrition quality, minutes exercised, and general physical and mental health. Agreeableness was negatively correlated with stress levels, while neuroticism was negatively correlated with sleep quality, positively correlated with stress levels, and negatively correlated with general physical and mental health. With respect to gender differences, female students were less likely to smoke, but were more likely to report a binge drinking episode in the week prior to the experiment, had lower BMI, reported worse nutrition quality, fewer minutes exercised, and lower levels of general mental health. Age was found to be negatively correlated with BMI. Lastly, reporting a happier childhood was negatively correlated with stress, positively correlated with sleep quality, negatively correlated with BMI and minutes exercised, and positively correlated with general mental health.

In order to shed more light on possible nonlinearities in the relationship of $\mathrm{D}$ with Alameda Seven health outcomes, plots of predicted probabilities of binarized outcomes over the range of the D risk measure are presented in Figure 2. As the regression results indicate substantial gender differences, plots for male and female students are presented.

The plots reveal that the probability of being a smoker increases with higher levels of D, for both female and male subjects. However, the probability of reporting better nutrition and more exercise also increases with higher levels of $\mathrm{D}$. The probability of reporting a binge drinking episode and better quality of sleep are almost identical across the whole range of possible levels of D. Lastly, the probability of reporting high stress levels and having a BMI $>23$ decreases with higher levels of $\mathrm{D}$. There are substantial gender differences in predicted probabilities for all Alameda Seven health behaviors. 

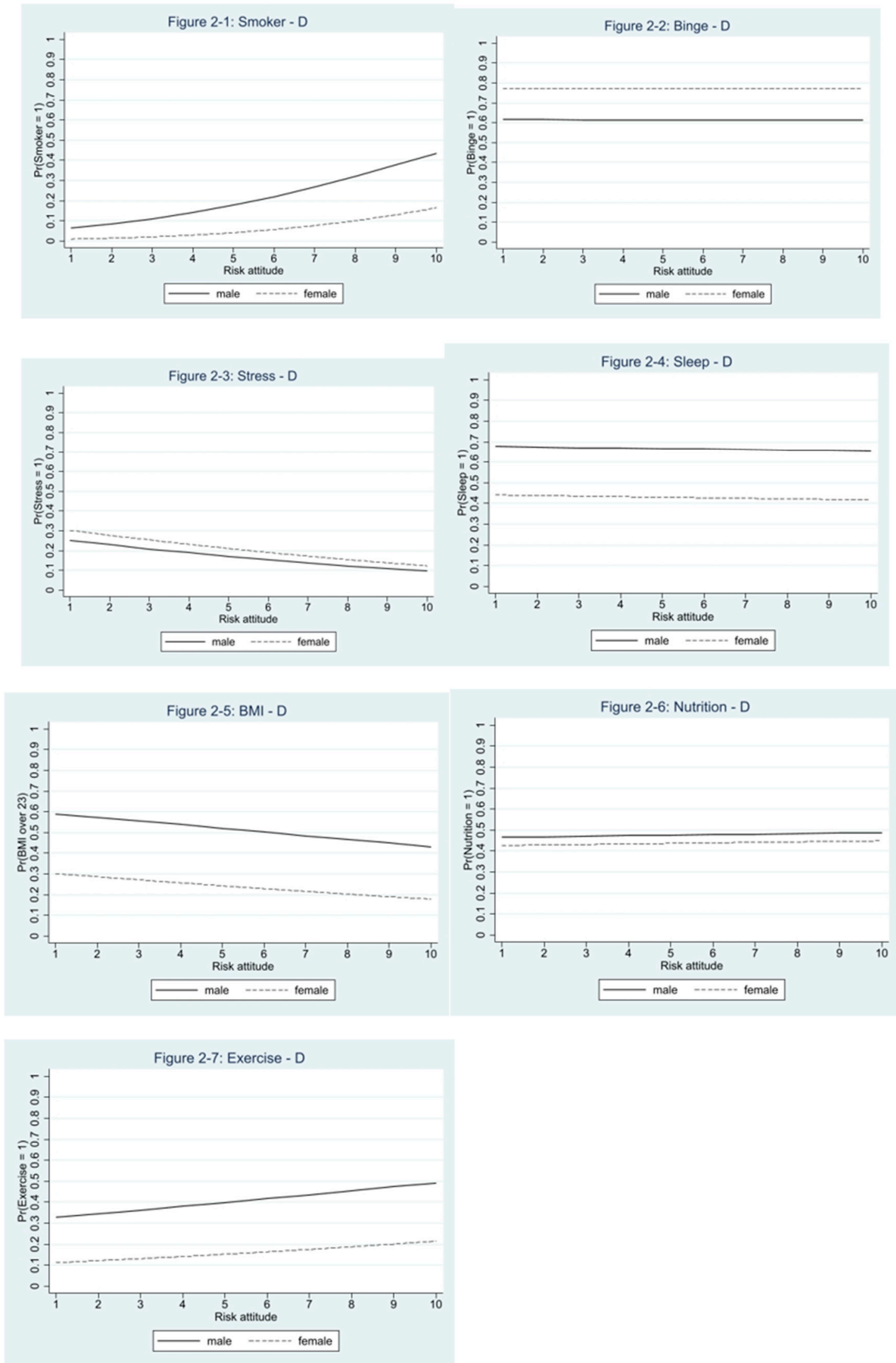

Figure 2. Plots of predicted probabilities by levels of D, for all Alameda Seven health behaviors. 


\section{Discussion}

The aim of this study was to test the suitability of a simple one-item risk attitude measure (D) as a predictor of the health behaviors known as the Alameda Seven. When controlling for the Big Five personality traits and cognitive ability, D predicted the probability of smoking and reporting higher stress levels, with no correlations found for the other Alameda Seven health behaviors. In addition, it also found relationships between Alameda Seven health behaviors and all Big Five personality traits except openness. Szrek et al. [29] first analyzed the predictive power of D in a sample of South African health center clients and found that it predicted smoking, problematic drinking, seat belt non-use, and risky sexual behaviors. Brailovskaia et al. [30] used a German sample and found that D predicted smoking and problematic drinking. The finding that $\mathrm{D}$ predicts smoking was confirmed in this research, but no effects were found for drinking and the other Alameda Seven health behaviors, suggesting that it is less suitable as a predictor of health behaviors for targeted prevention programs for college students. Plots of predicted probabilities of engaging in the health behaviors analyzed in this research by levels of $D$ revealed that the probability of smoking increases with higher levels of $\mathrm{D}$, for both female and male subjects, as predicted by human capital theory. The probability of reporting a BMI $>23$ decreases with higher levels of $\mathrm{D}$, which is also in line with the predictions of human capital theory.

However, the probability of reporting better nutrition and more exercise also increases with higher levels of $\mathrm{D}$, and the probability of reporting high stress levels decreases with higher levels of D. Lastly, the probability of reporting a binge drinking episode and better quality of sleep are almost identical across the whole range of possible levels of $D$. These findings are not in line with the predictions of human capital theory.

With respect to the Big Five personality traits, earlier studies suggested that correlations seemed to be strongest for conscientiousness and neuroticism [34,36], but Weston et al. [37] also found relationships between extraversion, agreeableness, conscientiousness, and neuroticism with individual diseases, such as hypertension or diabetes. This research found relationships between Alameda Seven health behaviors and all Big Five personality traits except openness, confirming those previous research findings.

For cognitive ability and its possible impact on health behaviors and outcomes, Deary [52] suggested that one possible transmission pathway between early-life ability and later-life health outcome was a different probability of adopting health-related behaviors, but that "a clear chain of causation from intelligence to health outcomes and then to death has not emerged." Auld and Sidhu [38] found that cognitive ability was positively correlated with health status; Harris et al. [41] found that childhood IQ was positively correlated with old-age health status; and Bijwaard et al. [39] found that a selection effect based on measures of ability accounted for about half of the raw differences in mortality in a Dutch sample. Wraw et al. [40] found that cognitive ability was positively correlated with physical health and negatively correlated with the probability of suffering from chronic health conditions, e.g., diabetes, between the ages of 49-55. Fawns-Ritchie et al. [42] found that cognitive ability was negatively correlated with the probability of currently smoking, but not with the probability of ever having smoked. This research found that cognitive ability was positively correlated with nutrition quality, but no relationships were found with the other Alameda Seven health behaviors or health outcomes. A tentative reason for this might be the fact that unlike in previous literature, only a one-item measure of cognitive ability was used in this study.

The previous evidence that $\mathrm{D}$ predicts smoking was confirmed in this research, but no relationship was found between problematic drinking and the other Alameda Seven health behaviors. The first possible explanation for this is the fact that this research used a younger sample, compared to the existing research, and as longitudinal neuroimaging studies have shown, the human brain continues to mature until about age 25 [53-57], leading to differences in risk perception $[58,59]$. This might provide a possible reason for the lack of statistically significant correlations found in this research. Finally, intercultural differences 
in social norms regarding risk perception [60] might provide a tentative explanation, as the previous research used samples from South Africa and Germany.

Limitations of this study include the relatively small sample size and resulting lack of statistical power, which could also provide an explanation for small number of statistically significant correlations found in this research. In addition, while college students are an important group for the targeting of preventive efforts, replication studies drawing samples from the general population should be carried out in the future to investigate if the results found in this research can be generalized. Lastly, the measure of cognitive ability used in this research consists only of one item and while this item has been shown to be highly correlated with scores on other submodules of the WAIS and other widely-used intelligence tests [46,47], more precise measures should be used in future research on the topic.

\section{Conclusions}

This research found that, when controlling for Big Five traits and including a measure of cognitive ability, D was a statistically significant predictor of only two Alameda Seven health behaviors: the probabilities of being a smoker and experiencing higher stress levels, where the correlation was positive for smoking and negative for stress.

As D is a "cheap" risk measure, both in terms of the time required for its completion in surveys and the lack of a need for financial incentives, future research could involve more testing of its predictive power of health behaviors in large-scale surveys using more diverse samples. Lastly, as Bran and Vaidis [61] have pointed out, the development of new measures of risk-taking might be a promising avenue for further research and may eventually lead to the discovery of suitable simple markers for the targeting of preventive efforts, both in college students and other populations.

Funding: This research was funded by Yonsei University's Future-leading Research Initiative, grant number 2017-52-0070.

Institutional Review Board Statement: The study was conducted according to the guidelines of the Declaration of Helsinki, and approved by the Institutional Review Board of Yonsei University, Mirae Campus, protocol code 2018-52-0092, on 4 February 2018.

Informed Consent Statement: Informed consent was obtained from all subjects involved in the study.

Data Availability Statement: The data presented in this study are available on request from the corresponding author. The data are not publicly available due to data and privacy protection requirements.

Acknowledgments: Junho Lee, Minjeong Chae, Yejin Lee and Seri Park provided outstanding research assistance.

Conflicts of Interest: The author declares no conflict of interest. The funder had no role in the design of the study, in the collection, analyses, or interpretation of data; in the writing of the manuscript, or in the decision to publish the results. 


\section{Appendix A}

Table A1. Correlation matrix.

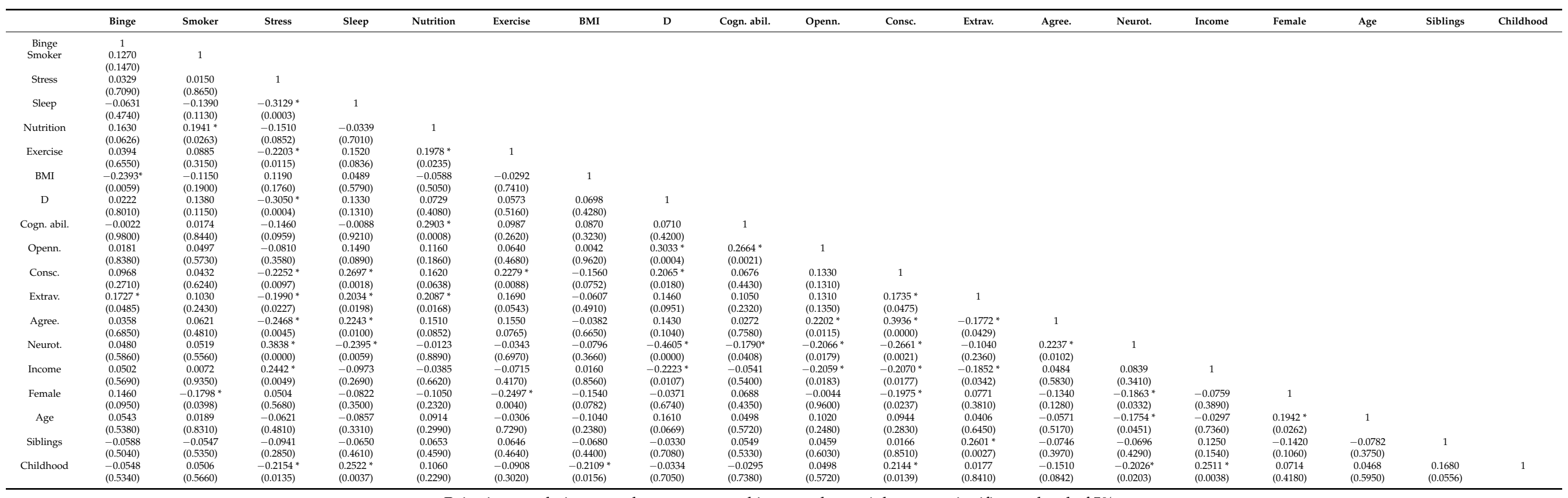

Pairwise correlations, $p$-values are reported in parentheses, ${ }^{*}$ denotes a significance level of $5 \%$. 
Table A2. All estimated coefficients.

\begin{tabular}{|c|c|c|c|c|c|c|c|}
\hline & Smoker & Binges & Stress & Sleep & BMI & Nutrition & Physical Activity \\
\hline & (probit) & (oprobit) & (oprobit) & (oprobit) & (oprobit) & (OLS) & (OLS) \\
\hline $\mathrm{D}$ & 0.1641 * & 0.0025 & $\underset{* *}{-0.1001}$ & 0.0051 & 0.0306 & 0.1012 & 0.6814 \\
\hline & $(0.0854)$ & $(0.0481)$ & $(0.0502)$ & $(0.0456)$ & $(0.0696)$ & $(0.1431)$ & $(7.7992)$ \\
\hline Cognitive ability & 0.0121 & -0.0050 & -0.0305 & -0.0122 & 0.0231 & $0.2051^{* * *}$ & 3.3423 \\
\hline measure & $(0.0325)$ & $(0.0206)$ & $(0.0213)$ & $(0.0193)$ & $(0.0280)$ & $(0.0605)$ & (3.2998) \\
\hline Big Five & 0.0163 & 0.0149 & 0.1447 & 0.0717 & 0.0034 & -0.0229 & -0.7798 \\
\hline Openness & $(0.1496)$ & $(0.0924)$ & $(0.0956)$ & $(0.0860)$ & $(0.1247)$ & $(0.2692)$ & (14.6737) \\
\hline Big Five & -0.0025 & 0.1717 & 0.0035 & 0.1274 & -0.2898 * & 0.1798 & 29.3221 \\
\hline Conscientiousness & $(0.1890)$ & $(0.1177)$ & $(0.1203)$ & $(0.1102)$ & $(0.1548)$ & $(0.3444)$ & $(18.7706)$ \\
\hline Big Five & 0.2660 * & 0.1470 * & -0.1040 & $0.1760 * *$ & 0.0592 & $0.5832 * *$ & $35.8987^{* *}$ \\
\hline Extraversion & $(0.1587)$ & $(0.0858)$ & $(0.0875)$ & $(0.0810)$ & $(0.1144)$ & $(0.2516)$ & $(13.7120)$ \\
\hline Big Five & 0.0017 & 0.0750 & -0.1998 * & 0.1223 & 0.0888 & 0.2833 & 20.0640 \\
\hline Agreeableness & $(0.1868)$ & $(0.1170)$ & $(0.1199)$ & $(0.1099)$ & $(0.1725)$ & $(0.3440)$ & (18.7537) \\
\hline Big Five & 0.2874 & 0.1055 & 0.2754 ** & $-0.1721 *$ & -0.1194 & 0.4543 & 11.2191 \\
\hline Neuroticism & $(0.1761)$ & $(0.1065)$ & $(0.1101)$ & $(0.0990)$ & $(0.1454)$ & $(0.3085)$ & (16.8147) \\
\hline Income measure & $\begin{array}{c}0.1876 \\
(0.1959)\end{array}$ & $\begin{array}{c}0.0868 \\
(0.1162)\end{array}$ & $\begin{array}{c}0.1668 \\
(0.1183)\end{array}$ & $\begin{array}{c}0.0270 \\
(0.1068)\end{array}$ & $\begin{array}{c}0.0032 \\
(0.1545)\end{array}$ & $\begin{array}{c}0.2291 \\
(0.3352)\end{array}$ & $\begin{array}{c}1.5024 \\
(18.2700)\end{array}$ \\
\hline $1=$ female & $\begin{array}{c}-0.8806^{* *} \\
(0.3507)\end{array}$ & $\begin{array}{l}0.3595^{*} \\
(0.2141)\end{array}$ & $\begin{array}{c}0.1272 \\
(0.2186)\end{array}$ & $\begin{array}{l}-0.2525 \\
(0.2013)\end{array}$ & $\begin{array}{c}-0.5666^{*} \\
(0.2901)\end{array}$ & $\begin{array}{c}-1.1696^{*} \\
(0.6269)\end{array}$ & $\begin{array}{c}-96.2704^{* * *} \\
(34.1706)\end{array}$ \\
\hline Age & $\begin{array}{c}0.0177 \\
(0.2147)\end{array}$ & $\begin{array}{c}0.0772 \\
(0.1211)\end{array}$ & $\begin{array}{c}0.0237 \\
(0.1269)\end{array}$ & $\begin{array}{l}-0.1520 \\
(0.1163)\end{array}$ & $\begin{array}{c}-0.3366^{*} \\
(0.2016)\end{array}$ & $\begin{array}{c}0.2592 \\
(0.3619)\end{array}$ & $\begin{array}{l}-26.2763 \\
(19.7291)\end{array}$ \\
\hline $\begin{array}{l}\text { Number of } \\
\text { siblings }\end{array}$ & $\begin{array}{l}-0.0785 \\
(0.2997)\end{array}$ & $\begin{array}{l}-0.1315 \\
(0.1589)\end{array}$ & $\begin{array}{l}-0.1289 \\
(0.1671)\end{array}$ & $\begin{array}{l}-0.0888 \\
(0.1520)\end{array}$ & $\begin{array}{l}-0.1888 \\
(0.2420)\end{array}$ & $\begin{array}{c}0.2606 \\
(0.4764)\end{array}$ & $\begin{array}{c}14.9250 \\
(25.9677)\end{array}$ \\
\hline Childhood & 0.2435 & -0.1847 & $-\underset{* *}{-0.2707}$ & 0.2238 * & $\begin{array}{c}-0.3457 \\
* *\end{array}$ & 0.4226 & -37.4131 * \\
\hline happiness & $(0.2334)$ & $(0.1327)$ & $(0.1372)$ & $(0.1247)$ & $(0.1746)$ & $(0.3885)$ & $(21.1765)$ \\
\hline /cut1 & & $\begin{array}{c}2.7226 \\
(2.7144)\end{array}$ & $\begin{array}{l}-3.3304 \\
(2.8490)\end{array}$ & $\begin{array}{l}-3.7321 \\
(2.6212)\end{array}$ & $\begin{array}{c}-7.7240 * \\
(4.1584)\end{array}$ & & \\
\hline / cut2 & & $\begin{array}{c}3.6324 \\
(2.7195)\end{array}$ & $\begin{array}{l}-1.4162 \\
(2.8035)\end{array}$ & $\begin{array}{l}-3.3807 \\
(2.5921)\end{array}$ & $\begin{array}{l}-6.5758 \\
(4.1450)\end{array}$ & & \\
\hline /cut3 & & $\begin{array}{l}5.0991^{*} \\
(2.7335)\end{array}$ & $\begin{array}{c}0.0421 \\
(2.8086)\end{array}$ & $\begin{array}{l}-2.4406 \\
(2.5663)\end{array}$ & & & \\
\hline / cut4 & & & & $\begin{array}{l}-1.7217 \\
(2.5614)\end{array}$ & & & \\
\hline /cut5 & & & & $\begin{array}{l}-1.0213 \\
(2.5588)\end{array}$ & & & \\
\hline /cut6 & & & & $\begin{array}{c}-0.1574 \\
(2.5570)\end{array}$ & & & \\
\hline /cut7 & & & & $\begin{array}{c}0.6064 \\
(2.5595)\end{array}$ & & & \\
\hline /cut8 & & & & $\begin{array}{c}0.8429 \\
(2.5633)\end{array}$ & & & \\
\hline / cut9 & & & & $\begin{array}{l}1.7038 \\
(2.6092)\end{array}$ & & & \\
\hline Constant & $\begin{array}{l}-6.5494 \\
(4.9922)\end{array}$ & & & & & $\begin{array}{c}-12.7238 \\
(7.9941)\end{array}$ & $\begin{array}{c}345.2195 \\
(435.7548)\end{array}$ \\
\hline Observations & 131 & 131 & 131 & 131 & 131 & 131 & 131 \\
\hline
\end{tabular}

$* * * * *$, and $*$ denote significance levels of $1 \%, 5 \%$, and $10 \%$, respectively. 
Table A3. Regressions with only basic background control variables.

\begin{tabular}{|c|c|c|c|c|c|c|c|}
\hline & Smoker & Binges & Stress & Sleep & BMI & Nutrition & Physical Activity \\
\hline \multirow{3}{*}{$\mathrm{D}$} & (probit) & (oprobit) & (oprobit) & (oprobit) & (oprobit) & (OLS) & (OLS) \\
\hline & 0.1178 * & 0.0079 & $-\underset{* * *}{-0.1455}$ & $0.0692 *$ & 0.0420 & 0.0968 & 4.0141 \\
\hline & $(0.0713)$ & $(0.0417)$ & $(0.0439)$ & $(0.0398)$ & $(0.0597)$ & $(0.1321)$ & $(7.0377)$ \\
\hline \multirow[t]{2}{*}{ Income measure } & 0.1220 & 0.0359 & $0.1910^{*}$ & -0.0565 & -0.0266 & 0.0824 & -10.1302 \\
\hline & $(0.1722)$ & $(0.1110)$ & $(0.1130)$ & $(0.1034)$ & $(0.1453)$ & $(0.3442)$ & (18.3440) \\
\hline \multirow[t]{2}{*}{$1=$ female } & $-0.7253^{* *}$ & 0.3481 * & 0.1285 & -0.2420 & -0.4405 * & -0.7835 & $-89.5387^{* * *}$ \\
\hline & $(0.3212)$ & $(0.1963)$ & $(0.1989)$ & $(0.1850)$ & $(0.2656)$ & $(0.6121)$ & (32.6207) \\
\hline \multirow[t]{2}{*}{ Age } & 0.0003 & 0.0954 & -0.0117 & -0.0982 & -0.3378 * & 0.3455 & -19.7821 \\
\hline & $(0.1966)$ & $(0.1198)$ & $(0.1242)$ & $(0.1149)$ & $(0.1953)$ & $(0.3811)$ & (20.3105) \\
\hline \multirow[t]{2}{*}{ Number of siblings } & -0.1499 & -0.1223 & -0.1739 & -0.0505 & -0.1702 & 0.3458 & 18.5647 \\
\hline & $(0.2905)$ & $(0.1578)$ & $(0.1635)$ & $(0.1509)$ & $(0.2307)$ & $(0.5027)$ & $(26.7876)$ \\
\hline \multirow[t]{2}{*}{ Childhood happiness } & 0.2122 & -0.0899 & $-\underset{* * *}{0.3500}$ & $0.3516^{* * *}$ & -0.3826 & 0.5974 & -16.2212 \\
\hline & $(0.2055)$ & $(0.1224)$ & $(0.1269)$ & $(0.1170)$ & $(0.1614)$ & $(0.3827)$ & (20.3930) \\
\hline /cut1 & & $\begin{array}{l}1.1213 \\
(2.4855)\end{array}$ & $\begin{array}{l}-4.1533 \\
(2.6236)\end{array}$ & $\begin{array}{l}-3.1075 \\
(2.4329)\end{array}$ & $\begin{array}{l}-7.3721 * \\
(4.0314)\end{array}$ & & \\
\hline \multirow[t]{2}{*}{ /cut2 } & & 2.0000 & -2.4039 & -2.8038 & -6.2886 & & \\
\hline & & $(2.4890)$ & $(2.5828)$ & (2.4103) & $(4.0232)$ & & \\
\hline \multirow[t]{2}{*}{ / cut3 } & & 3.4238 & -1.0481 & -1.9376 & & & \\
\hline & & $(2.4983)$ & $(2.5834)$ & $(2.3896)$ & & & \\
\hline \multirow[t]{2}{*}{ /cut4 } & & & & -1.2472 & & & \\
\hline & & & & $(2.3856)$ & & & \\
\hline \multirow[t]{2}{*}{ /cut5 } & & & & -0.5806 & & & \\
\hline & & & & $(2.3833)$ & & & \\
\hline \multirow[t]{2}{*}{ /cut6 } & & & & 0.2176 & & & \\
\hline & & & & $(2.3810)$ & & & \\
\hline \multirow[t]{2}{*}{ / cut7 } & & & & 0.9349 & & & \\
\hline & & & & $(2.3842)$ & & & \\
\hline \multirow[t]{2}{*}{ / cut8 } & & & & 1.1719 & & & \\
\hline & & & & $(2.3888)$ & & & \\
\hline \multirow[t]{2}{*}{ / cut9 } & & & & 2.0318 & & & \\
\hline & & & & $(2.4373)$ & & & \\
\hline \multirow[t]{2}{*}{ Constant } & -2.6225 & & & & & -3.3303 & 661.7326 \\
\hline & $(4.0147)$ & & & & & $(7.9052)$ & $(421.2722)$ \\
\hline Observations & 131 & 131 & 131 & 131 & 131 & 131 & 131 \\
\hline
\end{tabular}

$* * * * *$, and $*$ denote significance levels of $1 \%, 5 \%$, and $10 \%$, respectively.

Table A4. Regressions with only D.

\begin{tabular}{|c|c|c|c|c|c|c|c|}
\hline & Smoker & Binges & Stress & Sleep & BMI & Nutrition & Physical Activity \\
\hline & (probit) & (oprobit) & (oprobit) & (oprobit) & (oprobit) & (OLS) & (OLS) \\
\hline $\mathrm{D}$ & 0.1021 & 0.0095 & -0.1508 & 0.0635 * & 0.0463 & 0.1054 & 4.5035 \\
\hline & $(0.0644)$ & $(0.0401)$ & $(0.0421)$ & $(0.0382)$ & $(0.0539)$ & $(0.1270)$ & $(6.9072)$ \\
\hline /cut1 & & $-\underset{* *}{0.5258}$ & $-\underset{* * *}{2.9365}$ & $-\underset{* * *}{2.1037}$ & $1.1257^{* * *}$ & & \\
\hline & & $(0.2412)$ & $(0.3728)$ & $(0.4118)$ & $(0.3215)$ & & \\
\hline / cut2 & & 0.3311 & $-\underset{* * *}{-1.3114}$ & $-\underset{* * *}{-1.8374}$ & $2.1280 * * *$ & & \\
\hline & & $(0.2397)$ & $(0.2591)$ & $(0.3397)$ & $(0.3708)$ & & \\
\hline /cut3 & & $1.7377^{* * *}$ & -0.0399 & $-\underset{* * *}{-1.0084}$ & & & \\
\hline & & $(0.2871)$ & $(0.2434)$ & $(0.2473)$ & & & \\
\hline / cut4 & & & & $\begin{array}{l}-0.3415 \\
(0.2300)\end{array}$ & & & \\
\hline /cut5 & & & & $\begin{array}{c}0.2872 \\
(0.2296)\end{array}$ & & & \\
\hline
\end{tabular}


Table A4. Cont.

\begin{tabular}{|c|c|c|c|c|c|c|c|}
\hline & Smoker & Binges & Stress & Sleep & BMI & Nutrition & Physical Activity \\
\hline /cut6 & & & & $\begin{array}{c}1.0368^{* * *} \\
(0.2396)\end{array}$ & & & \\
\hline /cut7 & & & & $\begin{array}{c}1.7320 * * * \\
(0.2653)\end{array}$ & & & \\
\hline /cut8 & & & & $\begin{array}{c}1.9670^{* * *} \\
(0.2806)\end{array}$ & & & \\
\hline / cut9 & & & & $\begin{array}{c}2.7982^{* * *} \\
(0.4334)\end{array}$ & & & \\
\hline Constant & $\begin{array}{c}-1.7784^{* * *} \\
(0.4031)\end{array}$ & & & & & $\begin{array}{c}5.8768^{* * *} \\
(0.7357)\end{array}$ & $\begin{array}{c}148.7372 * * * \\
(40.0217)\end{array}$ \\
\hline Observations & 131 & 131 & 131 & 131 & 131 & 131 & 131 \\
\hline
\end{tabular}

$* * * * *$, and $*$ denote significance levels of $1 \%, 5 \%$, and $10 \%$, respectively.

\section{Appendix B. Experimental Procedures, WAIS Tasks, Big Five Personality Trait Items, Health and Background Questionnaires}

All data used in this research were collected in a paper-and-pencil experiment. Subjects were freshmen students on a college campus in the Republic of Korea who were recruited using posters on campus and social network services.

In all three experimental sessions, subjects were seated apart and then welcomed to the experiment. The first two tasks were the Animal Naming Task and the Symbol Correspondence Test, both taken from the Wechsler Adult Intelligence Scale, although the scores from the Symbol Correspondence Test could not be used for analysis.

Task 1: In the following $90 \mathrm{~s}$, write down as many animals as you can.

Task 2: In the following, you see symbols corresponding to numbers. Please fill in the symbols in the grid below. You have $90 \mathrm{~s}$.

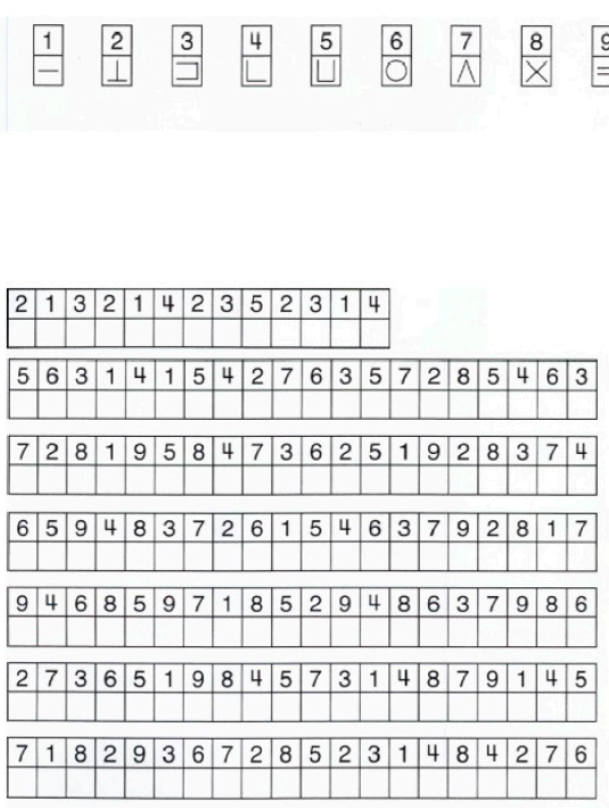

\section{Personality traits measurement}

The following section includes the wording of all questions used for Big Five personality traits measurement.

In the next section, we list several characteristics that an individual might have. Most likely, you will completely agree that some characteristics describe you well, while others don't, and you will be undecided on still others. Again, please indicate the degree to which 
the following statements are true for you, on a scale from 1 (not like me at all) to 7 (very much like me).

I am a person who...

Does a thorough job

Is talkative

Is sometimes rude to others

Is original, comes up with new ideas

Worries a lot

Has a forgiving nature

Tends to be lazy

Is outgoing, sociable

Values aesthetic, artistic experiences

Gets nervous easily

Does things efficiently

Is reserved

Is considerate and kind to almost everyone

Has an active imagination

Is relaxed, handles stress well

\section{Questionnaire on health behaviors and outcomes}

In general, would you say your health is... ?

1: Excellent

2: Very good

3: Good

4: Fair

5: Poor

In general, would you say your mental health is...?

1: Excellent

2: Very good

3: Good

4: Fair

5: Poor

\section{Stress}

Thinking about the amount of stress in your life, would you say that most of your days are...?

1: Not at all stressful

2: Not very stressful

3: A bit stressful

4: Quite a bit stressful

5: Extremely stressful

\section{Height/Weight}

How tall are you without shoes on?

How much do you weigh without clothes on?

\section{Sleep}

How often do you have trouble going to sleep or staying asleep?
1: Never
2: Rarely
3: Sometimes
4: Most of the time
5: All of the time 
How often do you find your sleep refreshing?

1: Never

2: Rarely

3: Sometimes

4: Most of the time

5: All of the time

How often do you find it difficult to stay awake when you want to?

1: Never

2: Rarely

3: Sometimes

4: Most of the time

5: All of the time

\section{Smoking/nicotine consumption}

At the present time, do you smoke cigarettes (including e-cigarettes) every day, occasionally or not at all?
1: Daily
2: Occasionally
3: Not at all

\section{Alcohol}

Now, some questions about your alcohol consumption.

A 'drink' refers to:

- a bottle or small can of beer, cider or cooler with $5 \%$ alcohol content, or a small draft;

- a glass of wine with $12 \%$ alcohol content;

- a glass or cocktail containing $1 \mathrm{oz}$. of a spirit with $40 \%$ alcohol content.

How often in the last week have you had [5 for males/4 for females] or more drinks on one occasion?
1: Never
2: Once
3: More than once
4: Every day

\section{Physical activity}

In the last 7 days, on which days did you do these recreational activities that made you sweat at least a little and breathe harder? Please only include activities that lasted a minimum of 10 continuous minutes.

1: Monday: minutes

2: Tuesday: minutes

3: Wednesday: minutes

4: Thursday: minutes

5: Friday: minutes

6: Saturday: minutes

7: Sunday: minutes

\section{Nutrition}

During the last week, on how many days have you eaten vegetables or have you drunk vegetable juice?

During the last week, on how many days have you eaten fruit or have you drunk fruit juice?

For all questions:

never

one day

two days 
three days

four days

five days

six days

every day

\section{Background questionnaire}

Please answer the following questions about yourself.

How difficult would it be for you to raise 100,000 Won for personal consumption?

Very difficult

Difficult

Neutral

Easy

Very easy

What is your major?

What is your gender? Female $\quad \square \quad$ Male $\quad \square \quad$ Prefer not to say

What is your year of birth?

Do you have siblings? If yes, how many?

On a scale from 1 to 5, how happy would you say your childhood was?

Very unhappy

Unhappy

Neither happy nor unhappy

Happy

Very happy

How willing are you to take risks, in general? Please rate your willingness to take risks on a scale from 1 to 10, where 1 corresponds to low and 10 corresponds to high willingness to take risks.

\section{References}

1. GBD 2019 Risk Factors Collaborators. Global burden of 87 risk factors in 204 countries and territories, 1990-2019: A systematic analysis for the Global Burden of Disease Study 2019. Lancet 2020, 396, 1223-1249. [CrossRef]

2. Ford, E.S.; Bergmann, M.M.; Boeing, H.; Li, C.; Capewell, S. Healthy lifestyle behaviors and all-cause mortality among adults in the United States. Prev. Med. 2012, 55, 23-27. [CrossRef] [PubMed]

3. Ding, D.; Rogers, K.; van der Ploeg, H.; Stamatakis, E.; Bauman, A.E. Traditional and emerging lifestyle risk behaviors and all-cause mortality in middle-aged and older adults: Evidence from a large population-based Australian cohort. PLoS Med. 2015, 12. [CrossRef] [PubMed]

4. $\quad$ Petersen, K.E.; Johnsen, N.F.; Olsen, A.; Albieri, V.; Olsen, L.K.; Dragsted, L.O.; Overvad, K.; Tjønneland, A.; Egeberg, R. The combined impact of adherence to five lifestyle factors on all-cause, cancer and cardiovascular mortality: A prospective cohort study among Danish men and women. Br. J. Nutr. 2015, 113, 849-858. [CrossRef] [PubMed]

5. Yusuf, S.; Reddy, S.; Ounpuu, S.; Anand, S. Global burden of cardiovascular diseases: Part I: General considerations, the epidemiologic transition, risk factors, and impact of urbanization. Circulation 2001, 104, 2746-2753. [CrossRef]

6. Shaw, J.E.; Sicree, R.A.; Zimmet, P.Z. Global estimates of the prevalence of diabetes for 2010 and 2030. Diabetes Res. Clin. Pract. 2010, 87, 4-14. [CrossRef]

7. NCD Risk Factor Collaboration (NCD-RisC). Trends in adult body-mass index in 200 countries from 1975 to 2014: A pooled analysis of 1698 population-based measurement studies with $19 \cdot 2$ million participants. Lancet 2016, 387, 1377-1396. [CrossRef]

8. Racette, S.B.; Deusinger, S.S.; Strube, M.J.; Highstein, G.R.; Deusinger, R.H. Weight changes, exercise, and dietary patterns during freshman and sophomore years of college. J. Am. Coll. Health 2005, 53, 245-251. [CrossRef]

9. Lloyd-Richardson, E.E.; Bailey, S.; Fava, J.L.; Wing, R. Tobacco Etiology Research Network. A prospective study of weight gain during the college freshman and sophomore years. Prev. Med. 2009, 48, 256-261. [CrossRef]

10. U.S. Department of Health and Human Services. Preventing Tobacco Use among Youth and Young Adults: A Report of the Surgeon General; U.S. Department of Health and Human Services, Centers for Disease Control and Prevention, Coordinating Center for Health Promotion, National Center for Chronic Disease Prevention and Health Promotion, Office on Smoking and Health: Atlanta, GA, USA, 2012.

11. Krieger, H.; Young, C.M.; Anthenien, A.M.; Neighbors, C. The epidemiology of binge drinking among college-age individuals in the United States. Alcohol Res. 2018, 39, 23-30. 
12. Flegal, K.M.; Carroll, M.D.; Ogden, C.L.; Curtin, L.R. Prevalence and trends in obesity among US adults, 1999-2008. JAMA 2010, 303, 235-241. [CrossRef] [PubMed]

13. Peto, R.; Darby, S.; Deo, H.; Silcocks, P.; Whitley, E.; Doll, R. Smoking, smoking cessation, and lung cancer in the U.K. since 1950; Combination of national statistics with two case-control studies. BMJ 2000, 321, 323-329. [CrossRef] [PubMed]

14. Lynagh, M.C.; Sanson-Fisher, R.W.; Bonevski, B. What's good for the goose is good for the gander. Guiding principles for the use of financial incentives in health behaviour change. Int. J. Behav. Med. 2013, 20, 114-120. [CrossRef]

15. den Engelsen, C.; Koekkoek, P.S.; Godefrooij, M.B.; Spigt, M.G.; Rutten, G.E. Screening for increased cardiometabolic risk in primary care: A systematic review. Br. J. Gen. Pract. 2014, 64, e616-e626. [CrossRef] [PubMed]

16. Si, S.; Moss, J.R.; Sullivan, T.R.; Newton, S.S.; Stocks, N.P. Effectiveness of general practice-based health checks: A systematic review and meta-analysis. Br. J. Gen. Pract. 2014, 64, e47-e53. [CrossRef]

17. Becker, G. Investment in human capital: A theoretical analysis. J. Political Econ. 1962, 70, 9-49. [CrossRef]

18. Grossman, M. On the concept of health capital and the demand for health. J. Political Econ. 1972, 223-255. [CrossRef]

19. Levhari, D.; Weiss, Y. The effect of risk on the investment in human capital. Am. Econ. Rev. 1974, 64, 950-963. Available online: https://www.jstor.org/stable/1815244 (accessed on 2 January 2021).

20. Johnson, W.R. A theory of job shopping. Q. J. Econ. 1978, 261-278. [CrossRef]

21. Gibbons, R.; Murphy, K.J. Optimal incentive contracts in the presence of career concerns: Theory and evidence. J. Political Econ. 1992, 100, 468-505. [CrossRef]

22. Dohmen, T.; Falk, A.; Huffman, D.; Sunde, U.; Schupp, J.; Wagner, G.G. Individual risk attitudes: Measurement, determinants, and behavioral consequences. J. Eur. Econ. Assoc. 2011, 9, 522-550. [CrossRef]

23. Belloc, N.B.; Breslow, L. Relationship of physical health status and health practices. Prev. Med. 1972, 1, 409-421. [CrossRef]

24. Kenkel, D.S. Health behavior, health knowledge, and schooling. J. Political Econ. 1991, 99, 287-305. [CrossRef]

25. Contoyannis, P.; Jones, A.M. Socio-economic status, health, and lifestyle. J. Health Econ. 2004, 23, 965-995. [CrossRef] [PubMed]

26. Balia, S.; Jones, A.M. Mortality, lifestyle, and socio-economic status. J. Health Econ. 2008, 27, 1-26. [CrossRef]

27. Schneider, B.S.; Schneider, U. Determinants and Consequences of Health Behaviour: New Evidence from German Micro Data. SSRN SOEP Paper No. 253. Working Paper; DIW: Berlin, Germany, 2009.

28. Humphreys, B.R.; McLeod, L.; Ruseski, J.E. Physical activity and health outcomes: Evidence from Canada. Health Econ. 2014, 23, 33-54. [CrossRef]

29. Szrek, H.; Chao, L.W.; Ramlagan, S.; Peltzer, K. Predicting (un)healthy behavior: A comparison of risk-taking propensity measures. Judgm. Decis. 2012, 6, 716-727. Available online: http://journal.sjdm.org/12/12727c/jdm12727c.html (accessed on 2 January 2021).

30. Brailovskaia, J.; Schillack, H.; Assion, H.J.; Horn, H.; Margraf, J. Risk-taking propensity and (un) healthy behavior in Germany. Drug Alcohol Depend. 2018, 192, 324-328. [CrossRef]

31. Friedman, H.S. Long-term relations of personality and health: Dynamisms, mechanisms, tropisms. J. Personal. 2000, 68, 1089-1107. [CrossRef]

32. Smith, T.W. Personality as risk and resilience in physical health. Curr. Dir. Psychol. Sci. 2006, 15, 227-231. [CrossRef]

33. Hampson, S.E.; Goldberg, L.R.; Vogt, T.M.; Dubanoski, J.P. Mechanisms by which childhood personality traits influence adult health status: Educational attainment and healthy behaviors. Health Psychol. 2007, 26, 121. [CrossRef] [PubMed]

34. Turiano, N.A.; Pitzer, L.; Armour, C.; Karlamangla, A.; Ryff, C.D.; Mroczek, D.K. Personality trait level and change as predictors of health outcomes: Findings from a national study of Americans (MIDUS). J. Gerontol. Ser. B Psychol. Sci. Soc. Sci. 2011, 67, 4-12. [CrossRef] [PubMed]

35. Bogg, T.; Roberts, B.W. The case for conscientiousness: Evidence and implications for a personality trait marker of health and longevity. Ann. Behav. Med. 2013, 45, 278-288. [CrossRef] [PubMed]

36. Friedman, H.S.; Kern, M.L. Personality, well-being, and health. Annu. Rev. Psychol. 2014, 65, 719-742. [CrossRef] [PubMed]

37. Weston, S.J.; Hill, P.L.; Jackson, J.J. Personality traits predict the onset of disease. Soc. Psychol. Personal. Sci. 2015, 6, 309-317. [CrossRef]

38. Auld, M.; Sidhu, N. Schooling, cognitive ability and health. Health Econ. 2005, 14, 1019-1034. [CrossRef]

39. Bijwaard, G.E.; van Kippersluis, H.; Veenman, J. Education and health: The role of cognitive ability. J. Health Econ. 2015, 42, 29-43. [CrossRef]

40. Wraw, C.; Deary, I.J.; Gale, C.R.; Der, G. Intelligence in youth and health at age 50. Intelligence 2015, 53, 23-32. [CrossRef]

41. Harris, M.A.; Brett, C.E.; Starr, J.M.; Deary, I.J.; Johnson, W. Personality and other lifelong influences on older-age health and wellbeing: Preliminary findings in two Scottish samples. Eur. J. Personal. 2016, 30, 438-455. [CrossRef]

42. Fawns-Ritchie, C.; Starr, J.M.; Deary, I.J. Health literacy, cognitive ability and smoking: A cross-sectional analysis of the English Longitudinal Study of Ageing. BMJ Open 2018, 8, e23929. [CrossRef]

43. Dohmen, T.; Falk, A.; Huffman, D.; Sunde, U. On the relationship between cognitive ability and risk preference. J. Econ. Perspect. 2018, 32, 115-134. [CrossRef] [PubMed]

44. Gerlitz, J.Y.; Schupp, J. Zur Erhebung der Big-Five-basierten Persoenlichkeitsmerkmale im SOEP. DIW Research Notes. 2005, 4. Available online: https://www.diw.de/de/diw_01.c.449451.de/publikationen/research_notes/2005_0004/zur_erhebung_der_ big-five-basierten_persoenlichkeitsmerkmale_im_soep.html (accessed on 2 January 2021). 
45. Lang, F.R.; John, D.; Ludtke, O.; Schupp, J.; Wagner, G.G. Short assessment of the Big Five: Robust across survey methods except telephone interviewing. Behav. Res. Methods 2011, 43, 548-567. [CrossRef] [PubMed]

46. Lang, F.R.; Hahne, D.; Gymbel, S.; Schröpper, S.; Lutsch, K. Erfassung des kognitiven Leistungspotenzials und der "Big Five" mit Computer-Assisted-Personal-Interviewing (CAPI): Zur Reliabilität und Validität zweier ultrakurzer Tests und des BFI-S. DIW Research Notes. 2005, 9. Available online: https://www.diw.de/de/diw_01.c.449734.de/publikationen/research_notes/2005_0 009/erfassung_des_kognitiven_leistungspotenzials_und_der_big_fi__litaet_und_validitaet_zweier_ultrakurzer_tests_und_ des_bfi-s.html (accessed on 2 January 2021).

47. Lang, F.R.; Weiss, D.; Stocker, A.; von Rosenbladt, B. Assessing cognitive capacities in computer-assisted survey research: Two ultra-short tests of intellectual ability in the German Socio-Economic Panel (SOEP). Schmollers Jahrbuch 2007, 127, 183-192.

48. Statistics Canada. Canadian Community Health Survey (CCHS). 2016. Available online: https://www23.statcan.gc.ca/imdb/p3 Instr.pl?Function=assembleInstr\&Item_Id=260675 (accessed on 24 November 2020).

49. Goldberg, L.R. A historical survey of personality scales and inventories. In Advances in Psychological Assessment; McReynolds, P., Ed.; Science and Behavior Books: Palo Alto, CA, USA, 1971; Volume 2, pp. 293-336. ISBN 9780831400262.

50. Goldberg, L.R. The structure of phenotypic personality traits. Am. Psychol. 1993, 48, 26. [CrossRef] [PubMed]

51. Seo, M.H.; Lee, W.Y.; Kim, S.S.; Kang, J.H.; Kang, J.H.; Kim, K.K.; Kim, B.Y.; Kim, Y.H.; Kim, W.J.; Kim, E.M.; et al. 2018 Korean Society for the Study of Obesity guideline for the management of obesity in Korea. J. Obes. Metab. Syndr. 2019, 28, 40. [CrossRef]

52. Deary, I. Why do intelligent people live longer? Nature 2008, 456, 175. [CrossRef]

53. Giedd, J.N.; Blumenthal, J.; Jeffries, N.O.; Castellanos, F.X.; Liu, H.; Zijdenbos, A.; Paus, T.; Evans, A.C.; Rapoport, J.L. Brain development during childhood and adolescence: A longitudinal MRI study. Nat. Neurosci. 1999, 2, 861-863. [CrossRef]

54. Sowell, E.R.; Thompson, P.M.; Tessner, K.D.; Toga, A.W. Mapping continued brain growth and gray matter density reduction in dorsal frontal cortex: Inverse relationships during postadolescent brain maturation. J. Neurosci. 2001, 21, 8819-8829. [CrossRef]

55. Sowell, E.R.; Thompson, P.M.; Holmes, C.J.; Jernigan, T.L.; Toga, A.W. In vivo evidence for post-adolescent brain maturation in frontal and striatal regions. Nat. Neurosci. 1999, 2, 859-861. [CrossRef]

56. Vijayakumar, N.; Allen, N.B.; Youssef, G.; Dennison, M.; Yücel, M.; Simmons, J.G.; Whittle, S. Brain development during adolescence: A mixed-longitudinal investigation of cortical thickness, surface area, and volume. Hum. Brain Mapp. 2016, 37, 2027-2038. [CrossRef]

57. Sussman, D.; Leung, R.C.; Chakravarty, M.M.; Lerch, J.P.; Taylor, M.J. The developing human brain: Age-related changes in cortical, subcortical, and cerebellar anatomy. Brain Behav. 2016, 6, e00457. [CrossRef] [PubMed]

58. Boyer, T.W. The development of risk-taking: A multi-perspective review. Dev. Rev. 2006, 26, 291-345. [CrossRef]

59. Romer, D. Adolescent risk taking, impulsivity, and brain development: Implications for prevention. Dev. Psychobiol. 2010, 52, 263-276. [CrossRef] [PubMed]

60. Benjamin, D.J.; Choi, J.J.; Strickland, A.J. Social identity and preferences. Am. Econ. Rev. 2010, 100, 1913-1928. [CrossRef] [PubMed]

61. Bran, A.; Vaidis, D.C. Assessing risk-taking: What to measure and how to measure it. J. Risk Res. 2020, 23, 490-503. [CrossRef] 